\title{
Experimentações com o cordel no jogo teatral
}

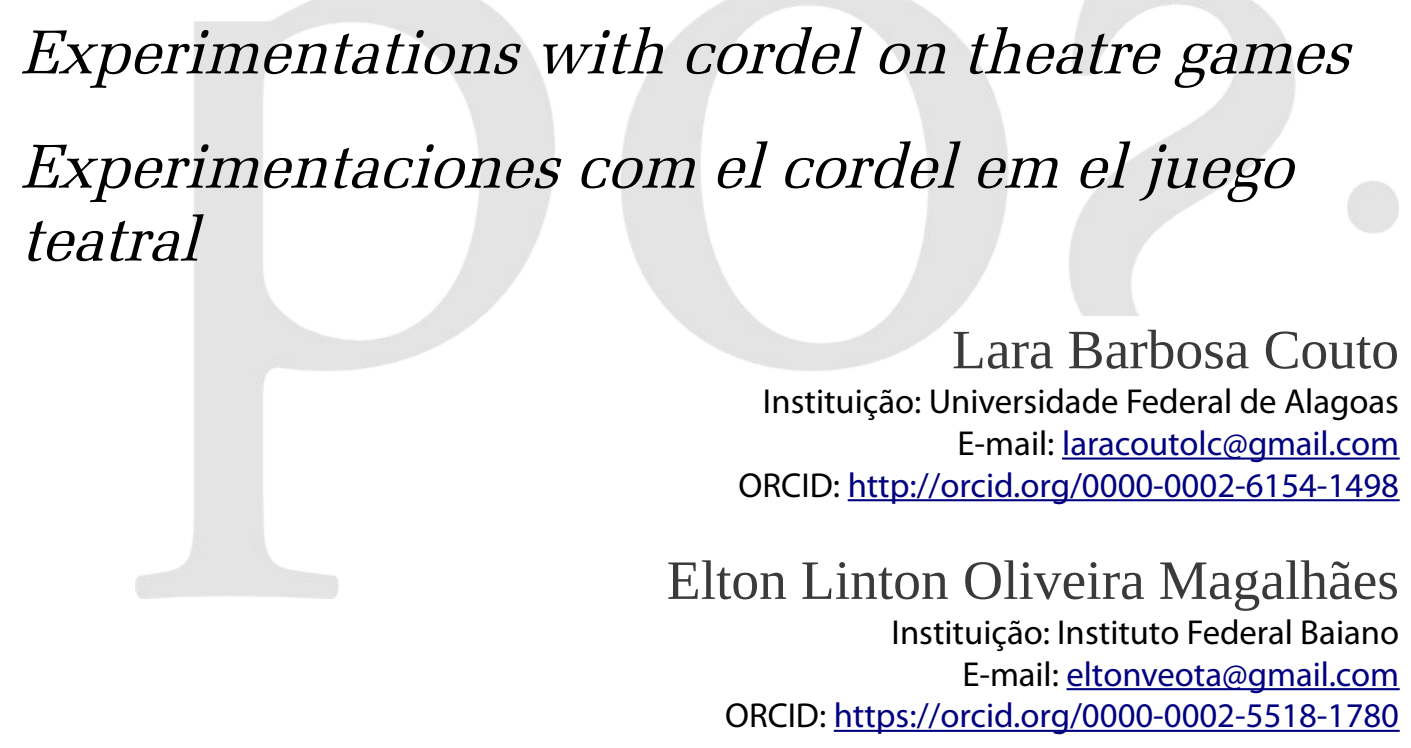

RESUMO:

Pretende-se analisar estratégias e abordagens de cruzamento entre o jogo teatral na sala de aula e a literatura de cordel, visando o aprimoramento dos estudantes em cena e uma aproximação com o cordel e suas características. Os procedimentos têm em vista uma experiência multidisciplinar na qual alunos participantes possam vivenciar aspectos fundamentais dos jogos teatrais e da literatura de cordel tradicional. A experimentação conjunta parte de aspectos fundamentais da escrita de cordel: a métrica e a rima, que se transformam em regras de jogo nas proposições metodológicas. Da mesma maneira, os aspectos fundamentais para os jogos spolinianos - o "quem", o "onde" e o "o quê" - podem servir de princípio para a produção de folhetos, incentivando a produção de dramaturgias em cordel.

Palavras-chave: Jogos Teatrais. Literatura de Cordel. Procedimentos criativos. Pedagogia das artes cênicas.

\section{ABSTRACT:}

It is intended to analyze interlacement strategies and approaches between theatre games in the classroom and cordel literature, aiming to improve the students' performance on stage as well as their acquaintance with cordel literature and its characteristics.

COUTO, Lara Barbosa; MAGALHÃES, Elton Linton Oliveira. Experimentações com o cordel no jogo teatral. PÓS:Revista do Programa de Pós-graduação em Artes da EBA/UFMG. v.10, n.20: nov.2020 Disponível em < https://doi.org/10.35699/2237-5864.2020.19897/>

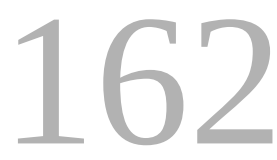


The procedures regard multidisciplinary circumstances in which the participating students may experience fundamental aspects of theatre games and traditional cordel literature. The combined experimentation originates from fundamental aspects of cordel writing: the metrics and rhyming, which become game rules within the methodological propositions. Likewise, the fundamental aspects of Spolin's games - the "who", the "where" and the "what" - may serve as foundations for the making of cordel literature pieces, stimulating cordel playwriting.

Keywords: Theatre Games. Cordel Literature. Creative Procedures. Performing Arts Pedagogy.

\section{RESUMEN:}

Se pretende analizar estrategias y enfoques de cruce entre el juego teatral en clase y la literatura de cordel, a fin de promover el progreso de los estudiantes en la escena y su aproximación con el cordel y sus características. Los procedimientos apuntan a una experiencia multidisciplinaria en la que los estudiantes participantes pueden experimentar aspectos fundamentales de los juegos teatrales y de la literatura tradicional de cordel. La experimentación conjunta parte de aspectos fundamentales del cordel: métrica y rima, que se convierten en reglas del juego en las proposiciones. Del mismo modo, los aspectos fundamentales para los juegos spolinianos - el "quién", el "dónde" y el "qué" - pueden servir como principio para la producción de folletos, fomentando la producción de dramaturgias en cordel.

Palabras clave: Juegos Teatrales. Literatura de Cordel. Procedimientos Creativos. Pedagogía de las Artes Escénicas. 
As reflexões em torno do uso pedagógico dos jogos e sua participação na aprendizagem e no desenvolvimento de competências e habilidades são uma recorrência em diversas áreas de estudo. Neste trabalho, pretende-se analisar possíveis estratégias e abordagens de cruzamento entre o jogo teatral na sala de aula e a literatura de cordel, visando o aprimoramento técnico dos estudantes em cena e uma aproximação com a linguagem do cordel e a aprendizagem de suas características.

A literatura de cordel, também chamada de literatura popular ou folheto de cordel, é um campo vasto inserido no universo da Literatura Brasileira e tem ligação forte com a cultura nordestina, especialmente em seus primórdios. Seu nome tem origem na Península Ibérica, mais especificamente em Portugal, porém sem maiores semelhanças entre o que era produzido lá e o cordel brasileiro. Enquanto o cordel português se referia a textos já consagrados, expostos em cordas e comercializados em forma de folhas avulsas, volantes, o cordel brasileiro se consolida com características estéticas próprias e peculiares. De acordo com Aderaldo Luciano (2010, p. 40), "o cordel português não era ou não foi resultado escrito do universo dos trovadores. Foi, isso sim, a forma mais fácil de propagar obras de escritores conhecidos na época". Quanto ao cordel brasileiro, a maioria das fontes concordam que ele tem origem, como ainda é hoje no final do século XIX, na cidade do Recife (que no período era um grande polo econômico e cultural) e tem como poeta fundador o paraibano Leandro Gomes de Barros, responsável pelo impulsionamento da produção impressa dos tradicionais folhetos de cordel no Brasil.

Segundo Ana Maria de Oliveira Galvão (2001, p. 45), em seus primeiros anos, até 1920, o cordel atende prioritariamente ao consumo de um segmento mais erudito da população, de pessoas letradas, que compravam as produções em livrarias. Posteriormente, o cordel migra de públicoalvo, atendendo a comunidades mais modestas, abarcando inclusive indivíduos analfabetos, que usufruíam dos folhetos através da escuta dos cordéis lidos em voz alta. Nesses contextos, o cordel circulava através da venda de exemplares, que eram pendurados em cordas para serem vendidos, costume que inclusive the atribui o nome. Exemplo disso é o poema biográfico do pernambucano João Cabral de Melo Neto, que em Descoberta da literatura descreve suas primeiras experiências com o texto literário através do cordel, pontuando que, ainda menino - porém letrado desde então

COUTO, Lara Barbosa; MAGALHÃES, Elton Linton Oliveira. Experimentações com o cordel no jogo teatral. PÓS:Revista do Programa de Pós-graduação em Artes da EBA/UFMG. v.10, n.20: nov.2020 Disponível em < https://doi.org/10.35699/2237-5864.2020.19897/>

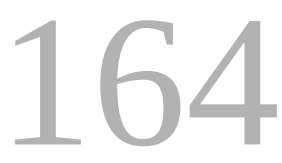


-, recebia folhetos populares que chegavam até ele por meio dos funcionários analfabetos da fazenda do seu avô. Cabia ao menino João fazer essas leituras e ativar o imaginário desses "cassacos do eito e de tudo", homens do povo.

\author{
E da feira do domingo \\ me traziam conspirantes \\ para que os lesse e explicasse \\ um romance de barbante. \\ Sentados na roda morta \\ de um carro de boi, sem jante, \\ ouviam o folheto guenzo, \\ a seu leitor semelhante, \\ com as peripécias de espanto \\ preditas pelos feirantes. \\ (MELO NETO, 1980, p. 75).
}

O folheto quase sempre apresenta conduções simples e diretas. Quando retrata uma narrativa, tende a colocar os fatos em ordem cronológica e se ater a um único enredo principal, características necessárias para a produção de um cordel desembaraçado:

\begin{abstract}
Para compor uma "história desembaraçada" é necessário evitar o acúmulo de personagens e de tramas, por isso é desaconselhável desenvolver enredos paralelos ou dar lugar a personagens secundários. Atendendo ao princípio da oração, suprimemse ou condensam-se as informações alheias à trama central, como a farta descrição que abre A Escrava Isaura, de Bernardo Guimarães, que se converte, na versão de Apolônio Alves dos Santos, em uma sucinta apresentação da localidade onde ocorre a ação. (ABREU, 2004, p. 205).
\end{abstract}

Comum também, mas não obrigatória, é a presença de xilogravuras na capa que elucidam o tema ao qual se refere o cordel e contribuem para tornar o folheto mais atrativo aos olhos do futuro comprador. Entretanto, é importante pontuar que a inserção da xilogravura nem sempre significou um avanço na apresentação estética dos folhetos. Os primeiros cordéis, quando não apresentados com "capas cegas", traziam vinhetas e adornos. A partir dos anos 20, João Martins de Athayde, o maior editor de folhetos do país na época, passou a recorrer a ilustradores e a clichês que reproduziam imagens e cartões postais, segundo o poeta e pesquisador Marco Haurélio (2010, p. 97). Somente a partir dos anos 50, a xilogravura passou a decorar as capas dos folhetos publicados, e, mesmo assim, sob protestos de escritores e leitores mais tradicionalistas.

COUTO, Lara Barbosa; MAGALHÃES, Elton Linton Oliveira. Experimentações com o cordel no jogo teatral. PÓS:Revista do Programa de Pós-graduação em Artes da EBA/UFMG. v.10, n.20: nov.2020 Disponível em < https://doi.org/10.35699/2237-5864.2020.19897/>

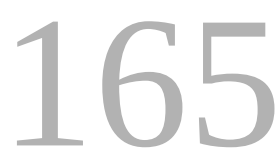


Considerando sua tradição no Nordeste, sobretudo no sertão - lugar de difícil acesso à informação durante muito tempo, pode-se afirmar que a disseminação do cordel contribuiu para dar maior protagonismo à população de baixa renda, que consumia e alimentava o mercado de venda dos cordéis: são os cordelistas, os folheteiros, os leitores, os mestres de gravura, para citar alguns. Sobre isso, comenta Márcia Abreu (2004, p. 1): "no caso dos folhetos, gente com pouca ou nenhuma instrução formal envolve-se intensamente com o mundo das letras, seja produzindo e vendendo folhetos, seja compondo e analisando versos, seja lendo e ouvindo narrativas".

Por muitas vezes, o cordel serviu como principal veículo de publicização de notícias, sobretudo em cidades mais afastadas. Para muitos dos leitores, a informação através do cordel, embora viesse de maneira mais simplista, era adaptada de acordo com o costume de apreciação do público, facilitando o entendimento e, por consequência, a disseminação das informações. Porém, isso não significa necessariamente que a produção de textos acontecia de forma displicente ou irresponsável: o rigor referente à rima, à métrica e à oração sempre foram fundamentais para um bom texto em cordel. Devido à sua estrutura rimada e versificada, além de sua linguagem de fácil acesso, o cordel favorecia a apreciação coletiva dos conteúdos apresentados, o que possibilitava a ventilação dos acontecimentos até mesmo em grupos de indivíduos iletrados. Sobre esse ponto, Marco Antônio Gonçalves destaca os desafios dos cordelistas, aos quais cabia:

[...] traduzir mundos, sejam próximos ou distantes, para sua forma poética, que lhe atribui plena significação e sensibilidade especiais, reforçando assim o próprio caráter de gênero que tem o cordel. Nesse sentido, o poeta, a partir da construção poética, traduz sensibilidades, fazendo com que mundos tão próximos ou aqueles distantes ganhem pelo relato, pela narrativa poética, um estatuto de linguagem que thes imprime uma nova sensibilidade de percepção, seja dos fatos corriqueiros e banais do dia a dia ou de fatos culturais estranhos ao mundo daqueles que escutam ou que leem a narrativa poética. (GONÇALVES, 2007, p. 35).

No contexto contemporâneo, as produções em cordel migram dos folhetos clássicos pendurados em barbantes e passam a habitar cada vez mais a internet, na qual os textos são publicitados em blogs, sites e redes sociais. O público-alvo também muda, enfraquecendo o seu direcionamento com a classe menos abastada e fortalecendo a identificação com um segmento mais intelectualizado da sociedade, estudantes, literatos e pesquisadores. Destaca-se também o desdobramento do cordel como objeto de interesse do turista, elemento que contribui na construção de um imaginário às vezes equivocado de Nordeste, já que a cada dia mais os seus temas têm se tornado

COUTO, Lara Barbosa; MAGALHÃES, Elton Linton Oliveira. Experimentações com o cordel no jogo teatral. PÓS:Revista do Programa de Pós-graduação em Artes da EBA/UFMG. v.10, n.20: nov.2020

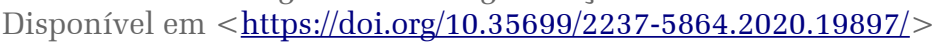

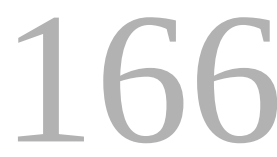


diversos. Segmentos do cordel começam a se desenvolver em ramos mais específicos, sendo cada vez mais comum a presença de folhetos atendendo a demandas da Educação em seus segmentos específicos do saber e tendo como alvo os estudantes. Serve de exemplo o livro Sala de versos e rimas (MAGALHÃES, 2019), organizado pelo professor e cordelista Elton Magalhães, que reúne cordéis sobre algumas áreas como a Sociologia, a Geografia, a Filosofia, a História, a Matemática e a Língua Portuguesa. O livro é uma iniciativa do Instituto Federal Baiano - Campus Itaberaba - e reúne escritos produzidos pelos próprios alunos, que passaram por uma oficina de produção de cordel para que houvesse a compreensão de sua estrutura tradicional. Para exemplificar, trouxemos um trecho do cordel Termos da Oração, produzido pela aluna Gabriela Nery:

\author{
Após falar do sujeito \\ Eu trarei o predicado \\ E o resto da oração \\ Pode ser interpretado \\ Complementando o verbo \\ Mas deixa o seu recado. \\ (NERY, 2019, p. 83, grifo nosso).
}

No que diz respeito à estrutura, a literatura de cordel é composta por estrofes que apresentam uma determinada quantidade de versos que se repetem, geralmente 6 (sextilhas, conforme o trecho acima citado), 7 (setilhas), 8 (oitavas ou oito pés de quadrão) ou 10 (décimas). Cada verso, por sua vez, apresenta sempre a mesma quantidade de sílabas, que podem ser 7 (heptassílabos), 10 (como é o caso do martelo agalopado) e 11 sílabas (a exemplo do galope à beira-mar). Interferem também, em cada um dos estilos, as cesuras, ou seja, as contagens silábicas, considerando a alocação das tônicas em espaçamentos específicos do verso, principalmente em formatos mais complexos, como o martelo agalopado (tônicas nas sílabas 3, 6 e 10) e o galope à beira-mar (tônica nas sílabas 2, 5, 8 e 11). Esses aspectos, que exigem certa destreza na elaboração dos versos e estrofes, solicitam do cordelista conhecimento a respeito de metrificação poética. No entanto, dentro da tradição popular, na qual muitos apreciadores eram analfabetos ou semianalfabetos, a habilidade na criação dos versos e o entendimento da métrica se dão pela afinidade com a rítmica intrínseca ao estilo do cordel, o que confere a cada folheto uma musicalidade específica a depender da quantidade de sílabas e da alocação das tônicas em sua estrutura básica. Por esse motivo, um apreciador de ouvido treinado consegue facilmente identificar um verso de péquebrado, como são chamados os versos que não possuem a mesma quantidade de sílabas

COUTO, Lara Barbosa; MAGALHÃES, Elton Linton Oliveira. Experimentações com o cordel no jogo teatral. PÓS:Revista do Programa de Pós-graduação em Artes da EBA/UFMG. v.10, n.20: nov.2020 Disponível em < https://doi.org/10.35699/2237-5864.2020.19897/>

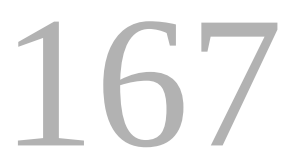


presentes na estrutura da escrita. Do artista que subverte as exigências da métrica e da cesura se diz que ele "cagou", gíria que denuncia a descontinuação do ritmo. Dito de outra forma, a rigidez do cordel clássico, com a mesma quantidade de versos em cada estrofe e a mesma quantidade de sílabas em cada verso, explicita um compromisso com dinâmica rítmica da performance oral, aspecto este que se torna ainda mais evidente quando se considera os gêneros de improviso, como a embolada e o repente.

Irmãos da literatura de cordel e também pertencentes ao universo da cultura popular, assim surgem o repente e a embolada. Ambos se configuram como gêneros de improvisação com acompanhamento musical. No primeiro, o instrumento mais característico é a viola. No segundo, o pandeiro. No desempenho, geralmente realizado em duplas, a apresentação se organiza na representação de um duelo, no qual cada uma das partes, alternadamente, apresenta seu conjunto de versos, constituindo assim o jogo de peleja.

As pelejas são desafios envolvendo dois ou mais cantadores, nos quais cada cantor/jogador propõe uma estrofe a ser superada por seu oponente. A peleja exige uma certa variação em relação aos tipos de estrofe, começando pela forma mais simples (sextilha) até chegar à mais complexa (galope à beira-mar), uma vez que o aumento da quantidade de estrofes e versos está relacionado a uma demonstração de habilidade em frente ao desafiante. No que diz respeito à divisão silábica, o rigor permanece, sendo inclusive um ponto crucial para a definição do artista mais proficiente.

No cordel, porém, a construção tende a se tornar mais cuidadosa, já que o seu modus operandi (produção escrita) possibilita uma maior reflexão a respeito do que é dito, diferentemente das pelejas e emboladas improvisadas, que têm um caráter de imediatismo nato. Vale ressaltar, porém, algumas peculiaridades da peleja no cordel em relação à embolada e ao repente. Para começar, a maioria das pelejas eternizadas nos folhetos são histórias fictícias e escritas por uma única mão, como é o caso da Peleja do Cego Aderaldo com Zé Pretinho, de Firmino Teixeira do Amaral, ou a Peleja de Manoel Riachão com o Diabo, de Leandro Gomes de Barros. Mesmo as diversas pelejas que são produzidas hoje, inclusive através das ferramentas digitais, estas sim de forma participativa, não possuem uma estrutura igual a das pelejas improvisadas. Só para dar um exemplo, em seus primórdios, as cantorias eram iniciadas com estrofes em quatro versos, as chamadas quadras. Tal estrutura nunca fez parte do universo do cordel. Ao longo do tempo, as sextilhas passaram não só a compor

COUTO, Lara Barbosa; MAGALHÃES, Elton Linton Oliveira. Experimentações com o cordel no jogo teatral. PÓS:Revista do Programa de Pós-graduação em Artes da EBA/UFMG. v.10, n.20: nov.2020 Disponível em < https://doi.org/10.35699/2237-5864.2020.19897/> 
as pelejas de improviso, como também se tornaram a forma inicial do jogo. Isso mostra que o texto em cordel na verdade foi quem influenciou a estrutura do repente, apesar de ainda existirem distinções quanto ao tipo de sextilha presente em ambas as modalidades: no cordel, as sextilhas têm 3 versos brancos (sem rimas), sendo estes os ímpares, e 3 versos que rimam entre si, os pares. Já na sextilha da peleja de improviso, o primeiro verso de cada sextilha deve rimar com o último da sextilha anterior. Segundo o pesquisador Aderaldo Luciano (2010),

esse artifício, da deixa, foi introduzido para que o público e os contendores garantissem que realmente a cantoria estava se desenrolando de improviso, sem o recurso do verso decorado. Cantar o verso decorado é desfeita imperdoável na cantoria improvisada [...] São raros os cordelistas que, ao escreverem uma peleja, observam o cumprimento da deixa, não por desconhecerem, mas para dar maior dinamismo ao folheto, pois é muito mais importante descrever os dons poéticos e o conhecimento intelectual [...]. (LUCIANO, 2010, p. 39).

De fundamental importância para o jogo performativo de peleja é a presença da plateia, para a qual o desempenho está voltado. O retorno dos espectadores, através de risos, aplausos ou vozes de incentivo, funciona como termômetro do jogo, sendo mais um indicador de qual participante se encontra em melhor situação. Na tentativa de cativar a plateia e desestabilizar o oponente, são comuns zombarias e xingamentos, que podem até mesmo atingir membros da audiência, endereçados ao opositor. Destaca-se, portanto, o aspecto da peleja como desempenho triangular, cuja uma das pontas, a plateia, apesar de ter participação indireta, influencia no desenvolvimento do jogo através de manifestações de riso e de encantamento.

Por mais que o cordel contribua na construção de um imaginário de Nordeste, as abordagens de sua literatura há tempos não se restringem apenas aos temas tipicamente nordestinos. Da mesma maneira, mesmo o cordel estando associado à cultura popular, não necessariamente suas abordagens refletem uma mentalidade do povo, ainda mais nos tempos atuais, nos quais é crescente a quantidade de cordelistas que compõe segmentos ditos mais eruditos da cultura, como universidades. $O$ que se observa em sua grande amplitude temática é a liberdade poética de muitos cordéis de reinventar acontecimentos históricos, inserindo personalidades públicas nos seus mais variados contextos, a exemplo dos cordéis $A$ chegada de Lampião no inferno (de José Pacheco), $A$ Morte de Bin Laden na boca do povo (de Antônio Barreto) ou A peleja de Lampião com Besouro Mangangá (de Victor Alvim Lobisomem). Essa fricção entre real e ficcional, entre acontecimento e

COUTO, Lara Barbosa; MAGALHÃES, Elton Linton Oliveira. Experimentações com o cordel no jogo teatral. PÓS:Revista do Programa de Pós-graduação em Artes da EBA/UFMG. v.10, n.20: nov.2020 Disponível em < https://doi.org/10.35699/2237-5864.2020.19897/>

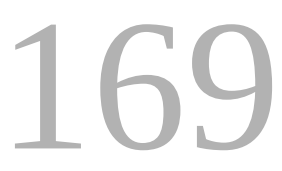


fantasia, é forte característica do jogo criativo do cordelista, que retrata, mas também inventa, não se restringindo à fidelidade histórica, preferindo agregar àquilo que aconteceu o que pode não ter acontecido, mas poderia vir a acontecer - a zona do possível e, por que não dizer, do impossível também. Prova disso são as centenas de folhetos publicados na época em que se constatou a morte de Lampião, este que é ainda hoje a personagem que mais aparece nos textos impressos. São diversas as versões contadas a respeito de sua morte, inclusive algumas notícias transformadas em cordel foram disseminadas ainda antes da sua morte ter sido realmente confirmada, segundo alguns pesquisadores. Assim, o cordel segue se reinventando, se adaptando às novas possibilidades de produção e divulgação, cumprindo com diversas funções sociais, porém nunca negando a tradição e uma preocupação com a manutenção dos seus traços essenciais que são a rima, a métrica e a oração.

\section{Cruzamentos teóricos}

No Brasil, o desenvolvimento de procedimentos e pesquisas voltados para a questão do jogo teatral sofre grande influência das proposições de Viola Spolin, por meio das obras Improvisações para o teatro e Jogos teatrais na sala de aula (SPOLIN, 2010a; 2010b). A autora estruturou uma abordagem metodológica de ensino do teatro na qual o jogo serve de instrumento de aprendizagem da linguagem teatral, de aprimoramento de habilidades para a contracena, além de desenvolvimento social e da capacidade de comunicação e expressão.

Quando se tem em mente a aprendizagem teatral através dos jogos de improvisação, observa-se a importância de uma alternância na participação do jogador nas funções de fazedor e de espectador. Tal variação explicita a necessidade de uso de recursos internos para a experimentação em cena, mas também para uma análise distanciada de seus princípios, que se dá através do desenvolvimento de uma sensibilidade para a fruição do jogo.

Pode-se afirmar isso também em relação à aprendizagem da performatividade em torno de expressões como o repente, a embolada e a leitura do cordel em voz alta. Como já pontuado, o rigor métrico intrínseco a tais manifestações transparece a necessidade de compreensão de um ritmo, de um determinado modo de dizer e organizar as palavras, habilidade que, em grande parte das

COUTO, Lara Barbosa; MAGALHÃES, Elton Linton Oliveira. Experimentações com o cordel no jogo teatral. PÓS:Revista do Programa de Pós-graduação em Artes da EBA/UFMG. v.10, n.20: nov.2020 Disponível em < https://doi.org/10.35699/2237-5864.2020.19897/>

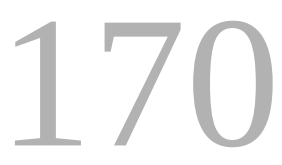


vezes, é aprimorada através da recepção. O desenvolvimento de uma sensibilidade de espectador torna-se parte preciosa da formação do artista que, na medida em que consome as apresentações públicas, também compreende melhor as nuances de relacionamento com a plateia.

Um ponto a ser destacado diz respeito ao encantamento, aspecto mágico do desempenho, em parte relacionado ao virtuosismo e ao alto grau de dificuldade das performances, mas também ao imaginário popular fantástico, no qual a religiosidade transita entre crendices, superstições e construções místicas. Serve de exemplo para melhor entendimento do termo esta colocação de Francisco Vilela (1980) a respeito do cantador de coco de embolada Torce Bola:

Torce Bola cantava muito, possuía uma voz magnífica e tinha uma facilidade assombrosa em pegar os cocos que os outros cantadores tiravam. Não havia jeito de ficar enganchado e de ficar calado como muitos e repetia admiravelmente toda entrega complicada que os outros cantadores inventavam. Foi em vista disso que se originou a lenda que afirmava que ele tinha pauta com o cão. (VILELA, 1980, p. 46).

Talvez seja importante acrescentar como hipótese, ou como observação pessoal, o fato de que o encantamento não se refere apenas ao domínio das técnicas necessárias ao desempenho, mas também a elementos mais difíceis de serem nominados, mas que são facilmente reconhecidos por quem consome a experiência. Há uma espécie de dilatação do fazer pelo magnetismo do artista em seu relacionamento com a plateia e a sua resposta durante a apreciação do acontecimento artístico. Experiências semelhantes também são vivenciadas no consumo do teatro e outras artes centradas no relacionamento direto entre artistas e espectadores; o que aponta para uma experiência descentralizada de um fazer específico, mas de qualidade de conexão que se instaura no instante do acontecimento.

Outra questão a ser levantada diz respeito à relação do encantamento com imersão de jogadores e espectadores à realidade do jogo. De acordo com Huizinga (2001, p. 6), é próprio do jogo a proposição de uma outra realidade, temporária, autônoma da vida cotidiana. O prazer de jogar, dentre outros fatores, estaria relacionado à evasão da realidade que ele propõe e à possibilidade de um alheamento temporário das questões do espaço e do tempo no qual o jogo se realiza. Nesse sentido, quanto mais encantado pelo desempenho, mais imerso dentro do universo do jogo, seja ele de representação, improviso ou desafio.

COUTO, Lara Barbosa; MAGALHÃES, Elton Linton Oliveira. Experimentações com o cordel no jogo teatral. PÓS:Revista do Programa de Pós-graduação em Artes da EBA/UFMG. v.10, n.20: nov.2020 Disponível em < https://doi.org/10.35699/2237-5864.2020.19897/>

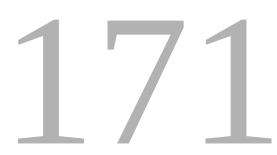


O jogo, destaca Huizinga, estabelece para os seus participantes uma ordem específica e absoluta. Ele é composto por uma legislação definida que interfere, inclusive, no objetivo dos seus jogadores. A dinâmica do jogo, portanto, oferece aos seus participantes liberdade e, ao mesmo tempo, ordem. Eles são livres em suas escolhas, desde que a ação não infrinja nenhuma das regras que regulam o funcionamento do jogo.

De acordo com Gilles Brougère (1998), a regulamentação é um dos fatores que conferem o desenvolvimento da criatividade. Apoiando-se nas teses de Chomsky, Brougère defende que a noção de criatividade é compatível à noção de regra, na medida em que nasce e se desenvolve em respeito a uma legislação. O criativo, apesar dos limites impostos pelo regulamento, se manifesta sempre que o indivíduo consegue produzir respostas novas a problemas que encontra, ao invés de meramente repetir o que os outros realizam. A regra, nesse sentido, contribui para canalizar os esforços criativos, dando-lhes um direcionamento.

Nas pelejas, ou nas apresentações de repente ou embolada, é muito comum, por exemplo, a escolha de um mote, ou seja, de um único universo temático a partir do qual os artistas organizam sua improvisação. O direcionamento específico do jogo dentro de um único universo temático possibilita uma maior investigação do assunto escolhido, que tem o seu entendimento explorado e destrinchado dentro da experiência prática. A escolha de um mote específico desafia os participantes para uma apropriação dos elementos que constituem o tema da investigação em variados contextos. A alternância de estímulos, a cada rodada do desafio, a partir das provocações do parceiro ou oponente, deflagra a necessidade de ajuste, de adaptação no desenvolvimento dentro do mote escolhido. Conforme aumenta o grau de dificuldade do desempenho, o jogador necessita de um maior domínio dentro da linguagem, além de estratégias para driblar as dificuldades encontradas e de destreza para sustentar a improvisação.

A respeito do coco de embolada, Eurides de Souza Santos e Katiuska Lamara dos Santos Barbosa (2014) questionam o real grau de imprevisibilidade dentro das improvisações. Para as autoras:

O improviso se pauta nas sistematizações construídas historicamente, que habilitam o embolador ou emboladora a (re) criar sua arte a cada nova performance uma reconstrução ou reconfiguração que conta com os conhecimentos e as ferramentas comumente utilizadas na arte do fazer. (BARBOSA; SANTOS, 2014, p. 68).

COUTO, Lara Barbosa; MAGALHÃES, Elton Linton Oliveira. Experimentações com o cordel no jogo teatral. PÓS:Revista do Programa de Pós-graduação em Artes da EBA/UFMG. v.10, n.20: nov.2020 Disponível em < https://doi.org/10.35699/2237-5864.2020.19897/>

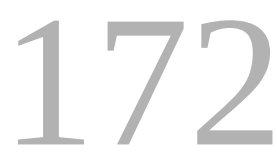


As sistematizações as quais Santos e Barbosa se referem deflagram uma jornada de experiências vividas antes de uma determinada atividade. Isso porque a prática do jogo possibilita o desenvolvimento de habilidades que potencializam jogos futuros, que alargam o vocabulário do jogador e possibilitam um maior domínio de repertório das possibilidades a serem usadas durante os desafios.

Experiência similar se estabelece nos jogos teatrais, dentro dos quais os jogadores, segundo Viola Spolin (2010a, p. 4), "desenvolvem as técnicas e habilidades pessoais necessárias para o jogo em si, através do próprio ato de jogar". A inventividade assim como a capacidade de solucionar problemas se potencializam dentro do processo do jogo, no ajuste espontâneo aos estímulos recebidos e dentro da necessidade de adequação às regras estipuladas. Para isso, é necessário um constante ajuste do foco, um dos elementos estruturantes para o jogo teatral. É ele que permite o arranjamento dos esforços interiores e exteriores para a obtenção dos objetivos do jogo. São outros sustentáculos: a instrução (a condução externa que possibilita um ajuste do jogo durante sua realização) e a avaliação, momento de reflexão sobre o desenvolvimento do jogo.

Ainda a respeito do foco, é possível fazer uma alusão às colocações de Fayga Ostrower (1977) a respeito da criatividade. A autora usa o termo "tensão psíquica" para se referir ao esforço canalizado, importante para a renovação e o desenvolvimento do potencial criador. Dentro do processo criativo, o artista vivencia um acúmulo energético direcionado à atividade, que se manifesta através de uma maior vitalidade psíquica, aspecto esse que pode ser desenvolvido e potencializado através do trabalho. Ostrower apresenta mais de uma vez a relação entre tensão psíquica e vitalidade da ação, pontuando que o objetivo do esforço criador não é o de descarregar a tensão, mas de manter a sua funcionalidade. Reconhecendo uma aproximação entre o que Ostrower chama de tensão psíquica e Spolin chama de foco, é possível compreender que o foco possibilita uma consciência mais aguçada da atividade, um reforço da concentração, um mergulho mais intenso dentro da realidade ficcional do jogo e associações mais complexas na resolução de problemas.

COUTO, Lara Barbosa; MAGALHÃES, Elton Linton Oliveira. Experimentações com o cordel no jogo teatral. PÓS:Revista do Programa de Pós-graduação em Artes da EBA/UFMG. v.10, n.20: nov.2020 Disponível em < https://doi.org/10.35699/2237-5864.2020.19897/>

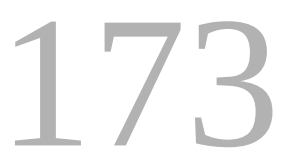




\section{Relatos da experiência}

Neste ponto do trabalho serão apresentados procedimentos visando uma experiência multidisciplinar na qual alunos participantes possam vivenciar aspectos fundamentais dos jogos teatrais e da literatura de cordel tradicional. O desenvolvimento das ações tem uma proposta de encaminhamento que visa a encenação de uma dramaturgia em cordel construída pelos próprios participantes, mas reconhece que este ponto não configura um aspecto obrigatório no planejamento da abordagem, que pode se centrar apenas no aperfeiçoamento do aluno/ator dentro de diferentes jogos e também numa melhor elaboração da prática da escrita e da produção de textos em cordel.

Dito isso, a primeira iniciativa de introdução do tema do cordel em sala de aula poderia ser uma conversa informal com os participantes do projeto, de modo a mensurar os diferentes níveis de familiaridade com o gênero literário e a compreensão de suas diversas características. Sobre esse ponto é interessante destacar que muitas pessoas possuem uma noção geral a respeito do cordel, mas não compreendem suas propriedades, acreditando erroneamente que o cordel seria apenas um tipo de texto de linguagem simples e rimada. A conversa inicial pede, portanto, um encaminhamento teórico a respeito da literatura de cordel, através de uma oficina, aula ou seminário que permita a desconstrução de falsos conceitos e a elucidação a respeito de seus traços, sua história e seu entrelaçamento com outras manifestações culturais, como o repente, a embolada e a xilogravura.

A partir de uma apresentação oral sobre o cordel e suas particularidades já é possível iniciar a experiência voltada ao jogo teatral, cujo ponto de partida sugere-se que seja um dos elementos mais fundamentais dos folhetos: a métrica e a rima. O entendimento da construção silábica em sete sílabas (septilha) tende a ser mais bem compreendido, como já dito anteriormente, a partir da percepção rítmica, ou seja, de uma percepção sobre a sonoridade que as sete sílabas imprimem ao desempenho oral. Assim, essa aproximação com a musicalidade intrínseca ao cordel pode ser apresentada originalmente a partir da leitura de folhetos, para depois ser experimentada em jogos com gramelô, língua inventada na qual o participante articula aleatoriamente diferentes sonoridades de forma a construir um fraseado de sete sílabas. Por exemplo, o jogo se inicia quando os participantes se dispõem em uma roda. O objetivo é a apresentação consecutiva de todos os participantes, na qual cada um precisa formular uma estrutura em gramelô que tenha sete sílabas e que rime com a

COUTO, Lara Barbosa; MAGALHÃES, Elton Linton Oliveira. Experimentações com o cordel no jogo teatral. PÓS:Revista do Programa de Pós-graduação em Artes da EBA/UFMG. v.10, n.20: nov.2020

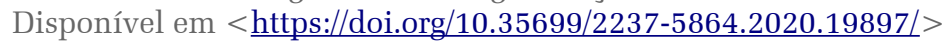

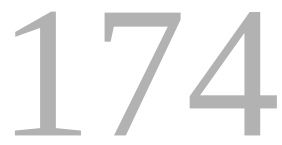


construção do participante anterior. Os demais participantes aguardam a sua vez de jogar e quando percebem que algum colega apresentou um verso de pé-quebrado (ou seja, com mais ou menos sílabas que sete) denunciam o erro a partir da expressão: "Cagou"! O participante que "cagou", por sua vez, paga uma prenda, dando a volta na roda.

O jogo a partir do gramelô é interessante por introduzir tanto a estrutura da septilha quanto a necessidade da rima. Convém aqui pontuar que é importante destacar aos alunos que nem todos os versos rimam entre si, e que na forma clássica há uma estrutura de rimas a ser respeitada. Ainda a respeito das rimas, um outro procedimento que permite um maior aperfeiçoamento da improvisação rimada é a proposição de pelejas, ou seja, de desafios entre participantes ou grupos nos quais cada parte pretende demonstrar maior habilidade para desenvolver um tema e rimar. $\mathrm{O}$ jogo consiste na separação de grupos (ele também pode ser realizado apenas com dois jogadores) e na definição de um tema, que serve de mote para as apresentações. Definido o assunto das falas, cada grupo apresenta uma livre quantidade de versos que atravessem a temática proposta e que rimem. Ganha o grupo que conseguir cumprir com as regras do jogo por mais tempo.

Na peleja de rimas, para não aumentar demais o grau de dificuldade dos jogos, o rigor em relação à métrica pode ser desconsiderado. No entanto, este configura a questão principal da proposição a seguir, que pode ser chamada de peleja de métrica. Esse jogo apresenta uma estrutura parecida com a da peleja de rimas, o que difere é o objetivo central, que desta vez seria a construção de versos em septilhas. Seguindo a mesma lógica apresentada no jogo anterior, com o interesse de não tornar a proposta muito complexa, o uso da rima pode ser desprezado inicialmente. Ambos os procedimentos, peleja de rimas e peleja de métrica, tendem a se fundir num momento mais avançado das experimentações, de modo a configurar um único jogo de improvisação à moda do repente e da embolada.

Em determinado momento, de preferência ao final de cada aula ou dia de oficina, sugere-se a improvisação de cenas a partir do cordel. Este configura um interessante momento da experiência, no qual os folhetos são lidos coletivamente e constituem um mote para a improvisação teatral. $A$ estrutura básica remete às proposições de Viola Spolin (2010a, p. 82-130), de modo que de cada cordel lido é necessário destacar qual o "quem" (personagens envolvidos), o "onde" (local onde se desenrola a ação) e "o quê" (situação dramática). Permite-se que alguns aspectos da improvisação

COUTO, Lara Barbosa; MAGALHÃES, Elton Linton Oliveira. Experimentações com o cordel no jogo teatral. PÓS:Revista do Programa de Pós-graduação em Artes da EBA/UFMG. v.10, n.20: nov.2020 Disponível em < https://doi.org/10.35699/2237-5864.2020.19897/>

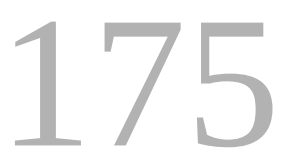


sejam previamente acordados entre as equipes que irão se apresentar. No entanto, as regras adicionais impostas à improvisação, ou seja, o elemento dificultador do jogo, só são ditas instantes antes de a prática começar. Sobre a improvisação a partir do cordel, é relevante destacar que a repetição dos jogos possibilita uma melhor compreensão sobre a evolução da turma, a apropriação dos elementos presentes no cordel e o jogo teatral pelos alunos, além de constituir um importante instrumento para uma reflexão sobre o desenvolvimento dos participantes tanto no âmbito da improvisação teatral quanto no âmbito do cordel.

O procedimento a seguir propõe uma inversão em comparação à proposta anterior. Desta vez a estrutura de um "quem", um "onde" e "o quê" serve de princípio para a construção literária, ou seja, para a produção de textos em cordel. Esses textos podem ser mais próximos da estrutura clássica de cordel, sem diálogos, ou tomar o direcionamento da escrita dramatúrgica. Escolhendo a segunda opção, o trabalho pode se tornar mais descomplicado com a inserção de um narrador, que pode explanar o desenvolvimento da ação entre um diálogo ou outro. Nesse caso, convém não acrescentar nenhuma regra de jogo, uma vez que a própria necessidade de metrificação e rima já constitui um desafio para a criação, que pode ser individual ou coletiva.

As estratégias apresentadas pretendem abarcar um desenvolvimento de mão dupla: do cordel para o jogo teatral, e do jogo teatral para o cordel. Dessa maneira, são trabalhadas habilidades voltadas para a resolução de problemas e o estar em cena, mas também são fomentadas competências referentes à leitura, à compreensão e à produção de textos. Seguindo esse progressivo direcionamento, é possível prever como resultado a produção de um ou vários textos dramatúrgicos que podem ser encenados na etapa final da disciplina/curso. Sendo esse o caso, sugere-se a continuidade da realização dos jogos teatrais durante o processo criativo, de modo a dar prosseguimento ao treinamento na área e como estratégia de construção das cenas. Por exemplo, durante os ensaios, a proposição de regras de jogo pode configurar um interessante dispositivo para a criação, reforçando o constante ajuste do foco. Também nessa etapa, outros sustentáculos da estrutura do jogo teatral spoliniano podem ser aprimorados, como a relação entre jogadores e o(a) instrutor(a) e as avaliações coletivas do desenvolvimento da experiência.

COUTO, Lara Barbosa; MAGALHÃES, Elton Linton Oliveira. Experimentações com o cordel no jogo teatral. PÓS:Revista do Programa de Pós-graduação em Artes da EBA/UFMG. v.10, n.20: nov.2020 Disponível em < https://doi.org/10.35699/2237-5864.2020.19897/>

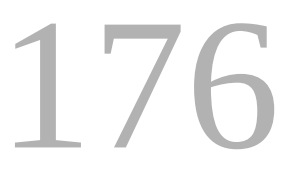




\section{Considerações finais: por que um jogo de cordel e uma criação textual lúdica?}

Este trabalho procurou reunir diferentes reflexões a respeito dos jogos teatrais e da literatura de cordel, assim como de possíveis abordagens pedagógicas visando o entrelaçamento desses dois universos. Por último, resta ainda debater sobre as motivações em torno da idealização de projetos como esse, assim como sua relevância artística e social.

O cordel é uma forma de expressão que retrata as ações e as manifestações de um povo, narrando suas conquistas e suas mazelas, criando e ressignificando os sentidos de seus cotidianos. Uma das características do cordel é sua condição de linguagem. Desde seus primeiros passos no Brasil, o cordel se apresenta com uma linguagem própria utilizada por conter e cantar o povo brasileiro, mais especificamente o povo nordestino. A cada dia que passa, ele tem conseguido quebrar as barreiras do preconceito e adentrar nas esferas múltiplas da educação e, conforme o faz, reforça-se o seu potencial como instrumento de aprendizagem e de autoexpressão. Experiências com o cordel em sala de aula, especialmente as que resultam numa produção textual pelos próprios participantes - a exemplo do já citado Sala de versos e rimas (MAGALHÃES, 2019) -, apontam para a relevância delas, nas quais o aluno é levado a assumir uma postura ativa diante do próprio processo educacional, colocando-se ativamente dentro da realidade na qual se insere, resolvendo problemas e desenvolvendo habilidades a partir de um esforço direcionado e motivado.

O desenvolvimento de jogos teatrais em sala de aula se insere num contexto similar, pois exige o engajamento de recursos físicos, cognitivos e afetivos para um melhor desempenho em diferentes situações, resultando num melhor desenvolvimento da capacidade de expressão e da oralidade. Não apenas isso, a prática de jogos não potencializa apenas o desenvolvimento de habilidades para o desempenho em cena, mas permite um aprimoramento de competências que atinge diversos âmbitos do conhecimento, de forma que alunos que vivenciam os jogos teatrais tendem a adquirir mais confiança em suas decisões e na aplicação do conhecimento em situações práticas; melhoram o relacionamento com os colegas; adquirem interesse por resolver problemas e vivenciam situações que requerem tomar decisões por conta própria. Ocorre, em outras palavras, um reforço da autonomia no processo de assimilação, apropriação e transformação do conhecimento, processo esse que se potencializa na variação do contexto e no questionamento. Através da vari-

COUTO, Lara Barbosa; MAGALHÃES, Elton Linton Oliveira. Experimentações com o cordel no jogo teatral. PÓS:Revista do Programa de Pós-graduação em Artes da EBA/UFMG. v.10, n.20: nov.2020 Disponível em < https://doi.org/10.35699/2237-5864.2020.19897/>

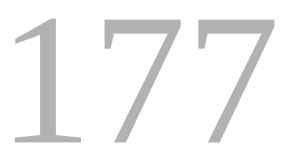


ação de contexto, a aprendizagem adquire um caráter mais empírico e possibilita a deflagração de lacunas ou pontos que podem ser mais bem compreendidos ou dominados. Já o questionamento contraria uma indesejável passividade no processamento das informações, de modo a desenvolver uma capacidade crítica diante dos acontecimentos. Para tanto, é importante destacar a importância das avaliações dentro da proposição spoliniana. A avaliação consiste num momento de elaboração intelectual da vivência, incentivando um posicionamento crítico e autônomo do que foi experienciado, para além da mera repetição de informações advindas dos professores.

Em suma, o entrelaçamento entre jogos teatrais e cordel no contexto educacional configura um exercício de dupla resistência. Resiste a tradição popular conforme se aproxima das novas gerações, não como suvenir cultural, mas como material de fruição intelectual de entendimento da realidade e como linguagem para uma expressão pessoal. Resiste também a Arte Cênica, por tantas vezes perseguida nos dias atuais, aqui inserida numa vivência de desenvolvimento de sujeitos e de iniciação de indivíduos ao universo das artes, contribuindo não apenas para a formação de novos artistas, mas também de novos espectadores, tão importantes para o fortalecimento cultural de qualquer país que pretenda vir a ser desenvolvido algum dia.

COUTO, Lara Barbosa; MAGALHÃES, Elton Linton Oliveira. Experimentações com o cordel no jogo teatral. PÓS:Revista do Programa de Pós-graduação em Artes da EBA/UFMG. v.10, n.20: nov.2020 Disponível em < https://doi.org/10.35699/2237-5864.2020.19897/>

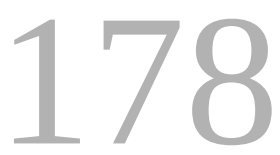




\section{REFERENCIAS}

ABREU, Márcia. Então se forma a história bonita - relações entre folhetos de cordel e literatura erudita. Horizontes Antropológicos, Porto Alegre, v. 10, n. 22, p. 199-218, 2004. Disponível em: <https://www.scielo.br/pdf/ha/v10n22/22701.pdf>. Acesso em: 23 out. 2020.

BARBOSA, Katiusca Lamara dos Santos; SANTOS, Eurides de Souza. "Canta quem sabe cantar": processos performativos na arte da embolada. Música em perspectiva, Curitiba, v. 7, n. 2, p. 61-83, dez. 2014. Disponível em: <http://dx.doi.org/10.5380/mp.v7i2.41504>. Acesso em: 23 out. 2020.

BROUGÈRE, Gilles. A criança e a cultura lúdica. In: KISHIMOTO, Tizuko Morchida. O brincar e suas teorias. São Paulo: Pioneira, 1998. p.19-32.

GALVÃO, Ana Maria de Oliveira. Cordel: leitores e ouvintes. Belo Horizonte: Autêntica Editora, 2001.

GONÇALVES, Marco Antonio. Cordel híbrido, contemporâneo e cosmopolita. Textos Escolhidos de Cultura e Arte Populares, Rio de Janeiro, v. 4. n. 1, p. 21-38, 2007. Disponível em: <https://www.epublicacoes.uerj.br/index.php/tecap/article/view/12604>. Acesso em: 23 out. 2020.

HAURÉLIO, Marco. Breve história da literatura de cordel. São Paulo: Editora Rodapé, 2010.

HUIZINGA, Johan. Homo Ludens. São Paulo: Perspectiva, 2001.

LUCIANO, Aderaldo. Apontamentos para uma história crítica do cordel brasileiro. São Paulo: Luzeiro, 2010.

MAGALHÃES, Elton. Entrevista com J. Borges. Blog Elton Magalhães, 21 abr. 2015. Disponível em: $<$ https://eltonmagalhaes.wordpress.com/2015/04/21/entrevista-com-j-borges/>. Acesso em: 30 de abr. 2020.

MAGALHÃES, Elton (Org.). Sala de versos e rimas. Salvador: Vento Leste, 2019.

MELO NETO, João Cabral de. A Escola das Facas. Rio de Janeiro: José Olympio, 1980.

NERY, Gabriela. Termos da Oração. In: MAGALHÃES, Elton (Org.). Sala de versos e rimas. Salvador: Vento Leste, 2019. p. 83.

OSTROWER, Fayga. Criatividade e processos de criação. Rio de Janeiro: Editora Vozes, 1977.

SPOLIN, Viola. Improvisação para o teatro. 4. ed. São Paulo: Perspectiva, 2010a.

SPOLIN, Viola. Jogos teatrais na sala de aula: um manual para o professor. 2. ed. São Paulo: Perspectiva, 2010b.

VILELA, Aloísio. O coco de Alagoas. Maceió: Museu Théo Brandão; UFAL, 1980.

COUTO, Lara Barbosa; MAGALHÃES, Elton Linton Oliveira. Experimentações com o cordel no jogo teatral. PÓS:Revista do Programa de Pós-graduação em Artes da EBA/UFMG. v.10, n.20: nov.2020 Disponível em < https://doi.org/10.35699/2237-5864.2020.19897/>

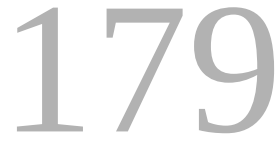


NOTAS

1 Como relatou o consagrado xilogravador e cordelista pernambucano J. Borges em entrevista a Elton Magalhães. Ver mais em: MAGALHÃES, 2015. 